\title{
Adult ESL Learners' Reading Fluency and Comprehension: An Insight
}

\author{
$\mathrm{Mei} \mathrm{Li}^{1}$ \\ ${ }^{1}$ Liaoning Technical University, Liaoning, China \\ Correspondence: Mei Li, Liaoning Technical University, Liaoning, China.
}

Received: June 19, 2018

doi:10.20849/aes.v3i3.448
Accepted: July 31, 2018

Online Published: August 14, 2018

\begin{abstract}
The present study aimed at exploring the elements affecting reading fluency and how to improve ESL learners' reading fluency and comprehension. It was attempted to find whether ESL learners would perform better when taught through top-down or bottom-up reading instruction model. 54 Chinese freshmen with the same level of reading proficiency tested through College Entrance Exam participated in this study. Two experiments were designed. Experiment 1 was reading fluency practice in classroom while experiment 2 was bottom-up vs. top-down model in Extensive Reading course. Bottom-up approach, a traditional teaching method was used in Class 1 in which students enjoyed independent silent reading and more flexibility of doing their reading homework. As for those in Class 2, students were assigned to top-down processing instruction model where the instructor carried out partner reading with regular after-class reading assignment. Then, the treatment was run and finally, both groups received a reading comprehension post-test. The data were collected and analyzed. The results revealed that reading aloud to a partner is an efficient way for improving fluency compared with silent reading; the more models of fluent reading the students hear the better. Meanwhile the study indicates routine checking up is also helping in building learners' fluency. The results also show that bottom-up training had a negative impact on fluency and comprehension. In contrast, top-down training positively affected fluency but had little impact on comprehension. These figures have implications for the type of language instruction used in actual classrooms. In light of these findings, the researcher also offered recommendations for ESL instructors.
\end{abstract}

Keywords: reading fluency, partner reading, silent reading, guidance, top-down instructional model, bottom-up

\section{Introduction}

The most important skill for second language learners in academic context is reading (Lynch\& Hudson, 1991, cited in Grabe2001).Thus, it can be concluded that perhaps the most fundamental skill to be taught for English majors in Chinese universities is reading comprehension and developing an appropriate level of reading skills, particularly comprehension, is essential for academic success (Akinwumiju, 2010; August, 2011; Iwai, 2009; Lukhele, 2013; Pretlow, 2009).

Reading accuracy or commonly known as word-reading accuracy refers to the ability to decode or recognize words correctly. The need for high accuracy is the reason why developing decoding skills is one of the important aspects of becoming a successful reader. Moktar et al., (2010) suggest that "in terms of vocabulary development...poor readers read less, become poorer readers, and learn few words"(p.78). The converse is that as competent readers read more, they learn more words and have better comprehension (Brantmeier, 2005; Foss, 2009).Fluency is the ability to read a text accurately, quickly, and with expression. Fluency is important because it provides a bridge between word recognition and comprehension. Therefore, fluency, reading in a fast and fluid manner, is what often distinguishes to observers the reading performance of a good reader from a bad one.

In recent years more researches have been made in China and several recommendations were suggested in the efforts to enhance ESL Learners' reading accuracy. But few focus on interconnections between reading fluency and comprehension. Despite its importance of skilled reading, fluency is often neglected in the classroom. Therefore, there is a need for ESL instructors to know about the importance of training students' reading fluency and different approaches they can use in classroom.

Unlike all previous experimental studies, this study is totally based on classroom activities. Participants are all students in China studying English as their majors from two normal classes in one university. The overall 
process was monitored by the instructor according to the teaching program and the data collected in the study were first hand. To fulfill the purpose of this study, the following research questions were addressed: a) Does reading fluency positively impact upon text comprehension? b) Does type of vocabulary training (top-down vs. bottom-up) improve reading fluency and comprehension?

\section{Literature Review}

Reading comprehension is the ability to process text, understand its meaning, and to integrate it with what the reader already knows. (William Grabe, 2009). An individual's ability to comprehend text is influenced by their skills and their ability to process information. As reading is an active process requiring word recognition and language comprehension (Foss, 2009; Gough, 1996; Jiang, Sawaki \& Sabatini, 2012), developing a sufficient level of learner vocabulary seems to be key to achieving this. One early quasi-experimental instruction study was conducted by Zimmerman (1997). Zimmerman found that meaningful repetitious use of words in interactive learning did have a positive impact on vocabulary acquisition and on reading development more generally. And research over the past two decades has also identified repeated reading as the key strategy for improving students fluency skills (NICHD, 2000). In addition, reading is a highly self-motivational activity and the inability to read well may lead to a loss of motivation and increased levels of frustration which, in turn, may also result in students reading less (Ahmad, 2011; Mokhtar et al., 2010; Rochecouste, Oliver, \& Mulligan, 2012). According to Breznitz and Berman (2003), fluency can be evaluated in two ways. The first way is by determining efficient word recognition and comprehension (Carver, 1990; Gough \& Tunmer, 1986). The second way of measuring fluency is by simply calculating word reading rate.

Models of the reading process which are called top-down and bottom-up try to explain and predict reading behavior. They are the bases on which reading instructions are built. According to Swaffer, Arans, and Byrnes (1991), a top-down model which focuses on the importance of background knowledge, builds global comprehension while a bottom-up model which emphasizes the linguistic clues, builds literal comprehension of a text. The top-down approach is based on the argument that reading comprehension requires more than simple linguistic knowledge, and that the use of schema theory is a key to unlocking comprehension, especially for second language learning.

\section{Method}

\subsection{Samples}

54 learners from 2 classes were chosen from Extensive Reading Course. They are all freshmen majoring in English. According to the first University Entrance Exam results carried out by the University (Liaoning Technical University in China), the distribution of the learners based on their English grades in two classes are illustrated in Table 1.

Table 1. Distribution of learners based on English grades

\begin{tabular}{lllll}
\hline Class & No. of learners & English Grade & & \\
\hline Class 1 & 27 & A 8 & B 13 & C 6 \\
Class 2 & 27 & A 9 & B 9 & C 9 \\
\hline
\end{tabular}

\subsection{Text Selection}

According to Alderson (2000), reading materials selected from familiar settings, on everyday topics, were likely to be easier to process than those that were not. The selection of the reading texts used in this study complies with this rule. All reading lists of words and sentences used in Experiment 1 are deliberately chosen by the instructor. All reading texts for Experiment 2 were CET reading materials ranging from level 2 to level 6 . Their suitability for ESL learners is at the tertiary level.

\subsection{Classroom Teaching Approach}

\subsubsection{Experiment 1: Guided and Repeated Oral Reading vs. Silent, Independent Reading}

\subsubsection{Time}

Every Monday and Friday morning (7:45am-8:00am) was allocated for oral reading . This study period is one semester. 


\subsubsection{Approach}

The instructor prepared the same reading lists of words and sentences for students in the two classes. At the same time a sample reading is recorded and shared through APP. In Class 1, students enjoyed more free reading pleasure. They were told to listen to the teacher's model reading and practice more after class by using Fanya Platform, but no guidance and feedback from both teacher and peers. In Class 2, students read the given materials aloud several times and received guidance and feedback from the teacher. Meanwhile a partner reading was arranged by the teacher. Students are required to finish 20 hours after-class online reading on Fanya Platform.

\subsubsection{Follow-up}

There is a designed timetable for everyday reading. Students should fill out the form including date \& time, reading material number, and reading partner's name. How often you use Fanya Platform and how long you are online will be recorded and reflected online.

\subsubsection{Oral Reading Fluency Assessment}

It was conducted on an individual basis in two minutes. Each learner was asked to read aloud a reading text in a normal way where his or her reading was recorded. During the test, the instructor will mark down the errors they made in pronunciation, separating clusters and their effort with speed. The students' levels of performance for reading fluency can be seen in Table 2 .

Table 2. Levels of performance for reading fluency

\begin{tabular}{llllll}
\hline Class & & Performance & & & \\
\hline & Excellent & very good & good & fair & Poor \\
Class 1 & 2 & 7 & 7 & 7 & 4 \\
Class 2 & 10 & 12 & 4 & 1 & 0 \\
\hline
\end{tabular}

\subsubsection{Experiment 2: Bottom-up Instructional Model vs. Top-Down Instructional Model}

\subsubsection{Research Procedure}

Reading texts were chosen from CET reading passages for both classes while two different approaches have been used in classroom teaching.

In Class 1 teaching, the activities might involve the learners answering these questions:

1) What is the verb?

2) What does the word "so" refer back to?

3) Can you guess the meaning of proclaim by understanding of affixation?

4) How could you make this sentence on its' own?

An underline understanding activity was carried out in this Class.

1) Tell students to scan the text and underline all of the unfamiliar words.

2) In the groups, students should compare the words that each of them underlined and work together to come up with possible meanings of the unfamiliar words. (At this point, students should not use a dictionary.)

3) Students should write the group approved definitions next to each word.

4) Ask each group to read their list of words.

5) Once all the words are on the board, ask the groups to share their definitions. (If possible, write the definitions on the board as well.)

6) Have the students read the text again.

In Class 2, the instructor may guide the students use their judgement and high-order thinking skills to strategically make sense of a text.

\section{Pre-reading}

--Stimulate discussion 
--Read the questions first

--Figuring words out from the context

--Previewing the text to get the gist

--Making predictions

While reading

--Monitoring

-- Paraphrasing

--True or false?

--Making new predictions based on new textual information

--Noticing Key Words/Key Statements/Topic Sentences

\section{After-reading}

-- Confirming predictions

-- Quiz time

-- Debate

--Thinking about what was learned

\subsubsection{Reading Fluency Assessment}

At the beginning of Fall Semester, the first oral reading fluency assessment was made in both classes and another was made at Spring semester. In this test, the students were allowed to read a passage containing about 350 to 600 words in 5 minutes. The differences on their levels of reading fluency can be seen in Table 3 . According to the percentage set by the instructor, students who can reach 97 WCPM will get 90 score while those with 45 WCPM or below will fail. The corresponding numbers of students on various levels were recorded at Fall Semester before Experiment 2 was carried out. At the beginning of Spring Semester when Experiment 2 had been successfully completed, their reading fluency levels were marked again. Table 4 shows their Reading Fluency improvement between Fall Semester and Spring Semester.

Table 3. Levels of performance for reading fluency

\begin{tabular}{llllll}
\hline Class & & Performance & & & \\
\hline & Excellent & Very good & good & fair & Poor \\
Class 1 & 4 & 7 & 10 & 4 & 2 \\
Class 2 & 13 & 12 & 2 & 0 & 0 \\
\hline
\end{tabular}

Table 4. Oral reading fluency data

\begin{tabular}{lllll}
\hline Class & \% ile & No. of students & Fall WCPM\# & Spring WCPM\# \\
\hline \multirow{4}{*}{ Class 1} & 90 & 4 & 97 & 100 \\
& 75 & 7 & 59 & 70 \\
& 60 & 10 & 29 & 42 \\
& 45 & 4 & 16 & 30 \\
& 20 & 2 & 8 & 10 \\
Class 2 & 90 & 13 & 97 & 116 \\
& 75 & 12 & 59 & 91 \\
& 60 & 2 & 29 & 60 \\
& 45 & 0 & 16 & 34 \\
\hline
\end{tabular}

WCPM (Words Correct Per Minute)

\subsubsection{Reading Comprehension Assessment}

Students were given four passages with 20 questions to be answered in 35 minutes. Four levels show the degree of difficulty (Level 1 from CET 2; Level 2from CET 3; Level 3 from CET 4; Level 4 from CET 6) 


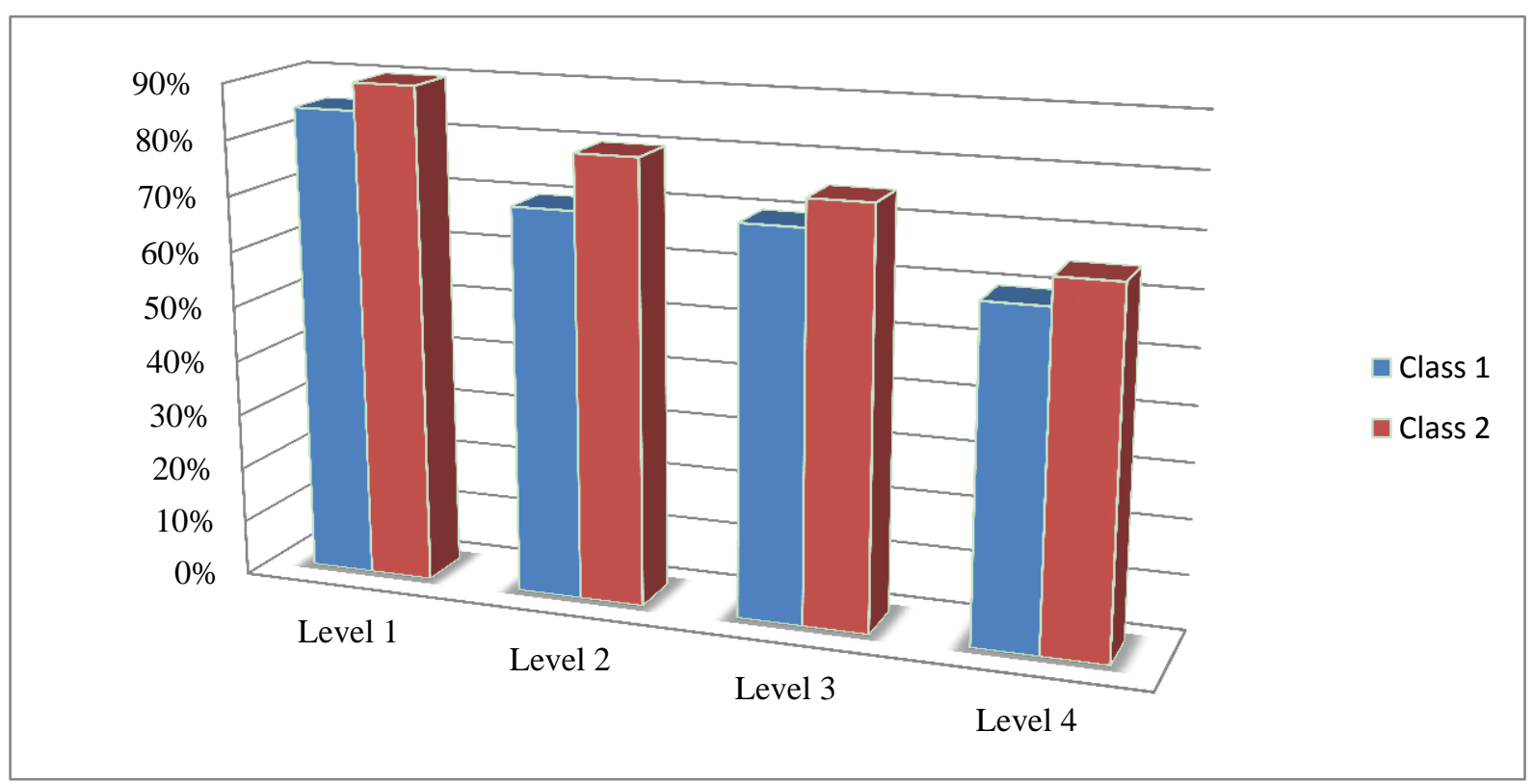

Figure 1. Comparison of reading comprehension

\section{Findings and Discussion}

As we can see from Table 1, samples taken from two classes have the same level of language ability. Table 2 shows that 11 students were badly needed to improve their reading fluency. The number of students whose performance is above good level in Class 2 is twice as much as that in Class 1. Based on the data collected from Experiment 1, we can conclude that repeated and monitored oral reading improves reading fluency and overall achievement, as does guided oral reading with appropriate teacher feedback. It also indicates that the readability of the reading texts is essential to reading fluency.

In Experiment 2 another reading fluency assessment was made to witness the impacts of bottom-up and top-down methods on reading fluency. It can be seen from Table 3 that all students reached satisfactory levels while 6 students still need further improvement to be good. A big difference is obvious in this study. It seemed that words taught in isolation were less readily retained in both short term and long term memory, and this may explain why it was more difficult for the participants to remember the same words when encountered in a new and embedded context. According to the statistics analysis in Table 4, we can witness an increasing of WCPM on all 5 levels. The figures implied that both bottom-up \& top-down methods can improve reading fluency. But the students in Class 2 improved their fluency by an average of 1.4 WCPM per week which is much higher than an average of 1.1 WCPM in Class 1.Therefore, top-down instructional model positively improved students' reading fluency.

An analysis of the results shown in Fig.1 shows that there is no significant difference between Class 1 and Class 2 in accuracy of reading comprehension. The findings of this study are not in line with a study done by Lynn et al.(2001) who consider oral reading fluency as an indicator of overall reading competence. It is somewhat surprising to the author. It might be that, as Nation, P (2002) suggests, while prior schemata knowledge may help readers to manage unknown vocabulary in context, the gain is in the short term only. This may be a weakness of the current investigation and is something that needs careful consideration in future studies.

\section{Conclusion}

The findings of the study highlight the importance of planning effective reading-fluency instructions to enhance learners' reading-fluency skills. Reading-fluency instructions should be classroom-friendly and can be easily integrated with literacy practice.

The findings further emphasize the importance of having model fluent reading. By listening to good models of fluent reading, students learn how a reader's voice can help written text make sense. And having students read aloud along with a model of well-paced, expressive reading and receiving specific feedback through systematic progress monitoring also helps improve students' fluency skills. Therefore, silent reading is not the best use of classroom time and partner reading is strongly recommended. 
It is also suggested that fluency will vary based on what kind of text is being read, how familiar the student is with the vocabulary, and how much practice they've had in reading aloud. Therefore, fluency rate (speed) is less important than accuracy and ease of reading. Several recommendations are put forward in this paper to serve as a basis for effective instructional practices in classroom such as Timed Reading, Recorded Reading, Performance Reading, and Mismatch Read Aloud etc.

Based on the findings of this study, it reveals that presenting training words first in a list did not transfer into the ability of the participants to read these words fluently and with comprehension when reading them next embedded in a text. In contrast to the bottom-up findings, a slight increase in reading fluency was found after the top-down contextualized training. However, in the current study there was no significant difference in comprehension, which is somewhat surprising. Even so, in terms of instruction it does seem that contextualized training may be more beneficial in the classroom than isolated training, at least in terms of fluency. In order to fully develop students reading skills, it is important to give students access to both bottom-up and top-down methods.

\section{Acknowledgements}

I place on record, my sincere thanks to my husband and daughter, for the continuous encouragement. I am also grateful to my friend Sun Ying. I am extremely thankful to her for sharing expertise, and sincere and valuable guidance and encouragement extended to me.

\section{References}

Ahmad, J. (2011). Intentional vs. incidental vocabulary learning. Interdisciplinary Journal of Contemporary Research in Business, 3(5), 67-75.

Akinwumiju, J.A. (2010). An analysis of basic academic skills associated with success in various areas of vocational education: A technique for planning academic programs. ProQuest Education Journals. (Order No. 3429804).

Alderson, J.C. (2000). Assessing reading. Cambridge: England Cambridge University Press. https://doi.org/10.1017/CBO9780511732935

Brantmeier, C. (2005). Non-linguistic variables in advanced second-language reading: Learners' self-assessment $\begin{array}{lllll}\text { and } \text { enjoyment. Foreign } & \text { Annals, }\end{array}$ https://doi.org/10.1111/j.1944-9720.2005.tb02516.x

Carver, R.P. (1990). Reading rate: A review of research and theory. San Diego, CA: Academic Press.

Foss, J.A. (2009). Individual differences and text genre in L2 French reading comprehension (304927740). ProQuest Education Journals (Order No. 336388).

Gough, P., \& Tunmer, W. (1986). Decoding and reading disability. Remedial Special Education, 7, 6-10. https://doi.org/10.1177/074193258600700104

Gough, P.B. (1996). How children learn to read and why they fail. Annals of Dyslexia, 46, 3-20. https://doi.org/10.1007/BF02648168

Grabe, W., \& Stoller, F. (2001). Reading for academic purposes: Guidelines for the ESL/EFL teacher. In M. Celce- Murcia (Ed.), Teaching English as a second or foreign language (3rd ed., pp. 187-205). Boston: Heinle \& Heinle Publishers.

Iwai, Y. (2009). Metacognitive awareness and strategy use in academic English reading among adult English as a second language (ESL) students. ProQuest Education Journals. (Order No. 3367175).

Jiang, X., Sawaki, Y., \& Sabatini, J. (2012). Word reading efficiency, text reading fluency, and reading comprehension among Chinese learners of English. Reading Psychology, 33(4), 323-349. https://doi.org/10.1080/02702711.2010.526051

Lukhele, B.B.S. (2013). Exploring relationships between reading attitudes, reading ability and academic performance amongst primary teacher trainees in Swaziland. Reading \& Writing, 4(1), 1-8. https://doi.org/10.4102/rw.v4i1.28

Lynch, B., \& Hudson, T. (1991). EST Reading. In M. Celce-Murcia (Ed.), Teaching English as a second or foreign Language (2nd ed., pp. 216-232). Boston: Heinle \& Heinle Publishers. 
Lynn, S.F., Douglas, F., Michelle, K.H., \& Joseph, R.J. (2001). Oral Reading Fluency as an Indicator of Reading Competence: A Theoretical, Empirical, and Historical Analysis. Scientific Studies of Reading, 5(3). http://doi.org/10.1207/s1532799XSSR0503-3

Mokhtar, A.A., Rawian, R.M., Yahaya, M.F., Abdullah, A., Mansor, M., Osman, M.I., ... Mohamad, A.R. (2010). Vocabulary knowledge of adult learners. English Language Teaching, 3(1), 71-80. https://doi.org/10.5539/elt.v3n1p71

Nation, P. (2002). Best practice in vocabulary teaching and learning. In J.C. Richards \& W.A. Renandya (Eds.), Methodology in language teaching: An anthology of current practice (pp.267-273). Cambridge: Cambridge University Press. https://doi.org/10.1017/CBO9780511667190.037

Pretlow, A.T. (2009). A study of the predictive value of oral reading fluency benchmarks to student success on the Georgia CRCT in reading comprehension for struggling readers. ProQuest Education Journals. (Order No. 3421363)

Rochecouste, J., Oliver, R., \& Mulligan, D. (2012). English language growth after university entry. International Journal of Educational Research, 53, 1-8. https://doi.org/10.1016/j.ijer.2011.11.005

Swaffar, J.K., Arans, K.M., \& Byrnes, H. (1991). Reading for meaning. Integrated approach to language learning. N Jersey: Prentice Hall.

William, G. (2009). Reading in a Second Language: Moving from Theory to Practice. Cambridge University Press.

Zimmerman, C.B. (1997). Do reading and interactive vocabulary instruction make a difference? An empirical study. TESOL Quarterly, 31(1), 121-140. https://doi.org/10.2307/3587978

\section{Copyrights}

Copyright for this article is retained by the author(s), with first publication rights granted to the journal.

This is an open-access article distributed under the terms and conditions of the Creative Commons Attribution license (http://creativecommons.org/licenses/by/4.0/). 